\title{
Arbitraje e interpretación contractual en el derecho ecuatoriano
}

César Coronel Jones*

Recibido/Received: 30/09/2019

Aceptado/Accepted: 01/10/2019

Sumario: 1. Introducción. 2. Las reglas del Código Civil: su naturaleza, prelación y destinatarios. 2.1 La detección de la intención común. 2.2 La interpretación gramatical. 2.3 La interpretación lógica y sistemática. 2.4 El método histórico. 2.5 La interpretación finalista. 2.6 El principio de la buena fe. 3. Posibilidad de una interpretación derogatoria.

Resumen: Con enorme frecuencia las controversias sometidas a arbitraje se relacionan con la interpretación contractual, e imponen a los árbitros la carga de realizarla. Las normas del Código Civil y las explicaciones de la doctrina marcan pautas fundamentales en dicho proceso. La interpretación, la calificación y la integración del negocio jurídico, permiten establecer la "regla negocial". Para su determinación, el texto, la intención común de las partes y la naturaleza del contrato son esenciales; pero también lo son la buena fe, como estándar objetivo de conducta y la carga de hablar claro que pesa sobre los redactores del contrato. La interpretación lógica sistemática, por su parte, es imperativa, pues la intención, que es el espíritu del contrato, es indivisible. El análisis histórico de la relación negocial y la aplicación que las partes hayan hecho del contrato, son otros auxiliares valiosos en la tarea interpretativa, que constituye un verdadero arte. Las normas

* Socio fundador de Coronel \& Pérez Abogados. Correo electrónico: ccoronel@coronelyperez.com

C. Coronel Jones, "Arbitraje e interpretación contractual en el derecho ecuatoriano", Revista Ecuatoriana de Arbitraje, No. 10, 2019, pp. 137-151. 
sobre la materia son una especie de caja de herramientas. Dependiendo del caso, habrá alguna de especial utilidad y las otras servirán de apoyo para confirmar lo apropiado de las conclusiones. En cualquier caso, jamas será aceptable un resultado contrario a la buena fe. Hay principios que se imponen incluso a la intención común de las partes, y este es uno de ellos. El proceso interpretativo, puede revestir considerable complejidad, de allí la conveniencia de aprovechar las luces que brinda la doctrina.

Palabras clave: interpretación, calificación, integración, regla negocial, buena fe.

\section{Arbitration and contractual interpretation in Ecuadorean law}

Aвstract: Frequently, arbitration controversies are related to contractual interpretation and impose arbitrators the burden to do so. The articles of the Civil Code and the explanations doctrine gives set fundamental guidelines in this process. The interpretation, conceptualization and integration of the legal agreement, allow to establish the applicable contractual provision. For its determination, the text, the common intention of the parties and the nature of the contract are essential; but so are the good will, as an objective standard of conduct and the burden to speak clearly relying on the drafters of the contract. The logic-systematic interpretation, on the other hand, is imperative since the intention, which is the spirit of the contract, is indivisible. The historical analysis of the legal agreement and the application of the contract the parties have made are valuable auxiliary tools in the interpretative task, which constitutes a true art. The rules on this subject can act as a toolbox. Depending on the case, a rule will be more useful, and the others will serve as a support to confirm how appropriate the conclusion are. In any case, an interpretation 
opposite to the good will principle will never be acceptable. There are principles imposing even to the common intention of the parties, and this is one of them. The interpretative process can be really complex, that is why it is convenient to take advantage of what the doctrine can provide.

KeYwORDs: interpretation of the contract, conceptualization of the contract, integration of the contract, applicable contractual provision, good will.

\section{INTRODUCCIÓN}

La interpretación contractual es un tema crucial del derecho de obligaciones y de la práctica jurídica. Para su adecuada realización se requiere determinar cuál fue la concreta voluntad de las partes contratantes al celebrarlo, pues es esa voluntad común original a la que hay que atenerse para establecer su contenido obligatorio por encima de lo literal de las palabras. Esta es la regla del art. 1576 del Código Civil, tomado del Napoleónico, modelo del sistema jurídico continental, que sigue rigiendo en buena parte del mundo.

Aunque el objetivo esencial de la interpretación es buscar y determinar cuál fue la voluntad real de los contratantes y la tarea de detectarla resulta primordial e impone desarrollar amplios análisis gramaticales, lógicos e históricos, la interpretación no se agota en ello, pues es obligatorio también aplicar el principio de la buena fe y otros criterios objetivos para fijar el contenido eficaz y el alcance obligatorio del contrato.

Pero hay más. En un sentido amplio, si entendemos como interpretación el fijar el alcance de la llamada "regla negocial", es decir, las normas u obligaciones concretas a que cada parte queda sujeta como consecuencia de la celebración del contrato, entonces debemos agregar a las tareas del intérprete las de realizar la calificación del contrato 
y su consecuente integración con las normas imperativas y supletorias que resulten aplicables.

\section{Las reglas del Código Civil: su naturaleza, PRELACIÓN Y DESTINATARIOS}

El Código Civil ecuatoriano regula la materia en el Título XIII del Libro IV, en los artículos 1576 a 1582, a los cuales se debe agregar el art. 1562 que establece el principio de buena $\mathrm{fe}^{1}$.

En cuanto a la naturaleza de estas reglas, hay dos aspectos que comentar. Lo primero es que contienen tanto criterios subjetivos como objetivos de interpretación. Así, estimo que son subjetivos los contenidos en los artículos $1576^{2}$, que prioriza la intención de las partes, y $1580^{3}$, que ordena la interpretación sistemática y armónica; y hay que tomar en cuenta otros contratos celebrados entre las mismas partes y sobre la misma materia así como la aplicación práctica que ellas hayan hecho del mismo.

Con respecto a los criterios de carácter objetivo, creo que el inciso segundo del art. $1582^{4}$ del Código Civil, que recogela llamada regla de "la carga de hablar claro" e impone que las cláusulas

1. Código Civil, Artículo 1562, RO Sup. No. 46, 24/06/2005.

Art. 1562.- Los contratos deben ejecutarse de buena fe, y por consiguiente obligan, no sólo a lo que en ellos se expresa, sino a todas las cosas que emanan precisamente de la naturaleza de la obligación, o que, por la ley o la costumbre, pertenecen a ella.

2. Ídem, Art. 1576.

Art. 1576.- Conocida claramente la intención de los contratantes, debe estarse a ella más que a lo literal de las palabras.

3. Ídem, Art. 1580.

Art. 1580.- Las cláusulas de un contrato se interpretarán unas por otras, dándose a cada una el sentido que mejor convenga al contrato en su totalidad.

Podrán también interpretarse por las de otro contrato entre las mismas partes y sobre la misma materia.

O por la aplicación práctica que hayan hecho de ellas ambas partes, o una de las partes con aprobación de la otra.

4. Ídem, Art. 1582.

Art. 1582.- No pudiendo aplicarse ninguna de las reglas precedentes de interpretación, se interpretarán las cláusulas ambiguas a favor del deudor.

Pero las cláusulas ambiguas que hayan sido extendidas o dictadas por una de las partes, sea acreedora o deudora, se interpretarán contra ella, siempre que la ambigüedad provenga de la falta de una explicación que haya debido darse por ella. 
ambiguas sean interpretadas en contra de quien las ha redactado, es una pauta objetiva, derivada del principio de buena fe.

Sobre el carácter objetivo o subjetivo de los criterios establecidos en los otros artículos del Título XIII se puede argüir con buenas razones en un sentido o en otro. Por último, hay dos criterios que estimo son simultáneamente subjetivos y objetivos: la buena fe y la interpretación finalista ${ }^{5}$, que disponen los artículos $1578^{6}$ y 15797. Más adelante trataré sobre ambos.

El otro punto que amerita ser comentado es la naturaleza obligatoria de las normas sobre interpretación contractual. Si bien la doctrina refiere un cuestionamiento del carácter de las mismas, pues hay quienes estiman que se trata de meros consejos o máximas de experiencia que la ley recoge para auxiliar al intérprete en su labor, existe una amplia aceptación al criterio de que se trata de verdaderas normas jurídicas cuya observancia es imperativa, "por lo cual su infracción o no aplicación habilita a plantear el recurso extraordinario de casación" ${ }^{\prime 8}$. En este mismo sentido se ha pronunciado la Corte Nacional de Justicia de nuestro país?

Con respecto a la prelación que debe existir entre los criterios subjetivos y objetivos, se ha sostenido ${ }^{10}$ que debe acudirse primeramente a los criterios subjetivos y que solo ante la imposibilidad de realizar la interpretación con tales criterios

5. Véase en este sentido, L. Diez-Picazo, Fundamentos del Derecho Civil Patrimonial, 6ta Ed., Editorial Aranzadi, 2007, pp. 496-497.

6. Código Civil, N. 1, Art. 1578.

Art. 1578.- El sentido en que una cláusula puede surtir algún efecto deberá preferirse a aquél en que no sea capaz de surtir efecto alguno.

7. Ídem, Art. 1579.

Art. 1579.- En los casos en que no apareciere voluntad contraria, deberá estarse a la interpretación que más bien cuadre con la naturaleza del contrato.

Las cláusulas de uso común se presumen aunque no se expresen.

8. G. Ordoqui Castilla, "Interpretación del contrato en el régimen uruguayo", en C. A. Soto Coaguila, J. L. De Los Mozos y De Los MOzos \& A. A. Alterini, Contratación Contemporánea, Editorial Palestra, 2001.

9. Véase, Colección de Jurisprudencia 2000-III-Civil, Fallo Civil 106-200.

10. Véase, L. Diez-Picazo, N. 5, p. 497. 
se debe acudir a los criterios objetivos; sin embargo, es claro que todos los criterios de interpretación pueden ser utilizados de manera concurrente y deben ser vistos como una caja de herramientas que la ley pone a la disposición del intérprete para que pueda realizar eficazmente su tarea. Abocado al caso concreto, que puede ser tan diverso como lo son los contratos, las partes, los estilos de redacción y más, el intérprete deberá analizar y escoger los criterios más apropiados al caso para utilizarlos en su labor.

Finalmente, encuantoalos destinatariosdelas normassobre interpretación, ellas son dirigidas primeramente a las partes, pues son quienes deben realizar la operación interpretativa, sea para cumplir adecuadamente las obligaciones del mismo, sea para exigir el cumplimiento de los otros contratantes.

Lainterpretación efectuada decomúnacuerdoporlas partes constituye la interpretación auténtica del contrato y puede tomar la forma de una nueva declaración complementaria. Si surgen controversias sobre la interpretación del contrato, será el juez o árbitro a quien se someta la controversia quien deberá aplicar las normas al menos sobre los puntos concretos en disputa para dirimir el conflicto.

\subsection{La detección de la intención común}

La actividad interpretativa propiamente dicha tiene como objeto principal determinar cuál fue la voluntad común de las partes contratantes.

Antes de entrar a analizar los métodos para realizar tal averiguación, conviene detenernos un poco en indicar en qué consiste esa intención común. Lo primero es que se trata de encontrar la voluntad concurrente de ambas partes y no las voluntades individuales de ellas.

Otro importante señalamiento es que lo que se busca determinar es la intención al momento de perfeccionarse 
el contrato y no lo que las partes quieren al momento de la interpretación, que puede ser distinto. La intención podría haber variado entre esos dos momentos y, de ser así, más que una interpretación auténtica, las partes deberían acordar una modificación al contrato.

Otro aspecto de interés es puntualizar que siendo la intención común aquello sobre lo que las partes consintieron, se debe tener en cuenta para determinarla, no solo lo declarado con palabras, sino también las conductas y comportamientos de las partes. Como ha señalado ORDOQUI ${ }^{11}$, el dogma del consenso tiene un "antes" y un "durante" que deben considerarse en la interpretación, y existen "comportamientos concluyentes" que pueden tener gran significación. A veces el silencio puede ser muy expresivo de una voluntad.

En la indagación de la intención común, lo natural es empezar con una revisión del texto del contrato, teniendo presente que inclusive para establecer que el sentido de las expresiones es claro se necesita realizar una actividad interpretativa.

Hay que advertir, sin embargo, que aun si se determina que el elemento literal es claro, la interpretación no puede detenerse allí. Un texto, en principio aparentemente claro, puede no serlo una vez cotejado con otros elementos $o$ materiales de interpretación. Incluso puede darse el caso de que la aparición de nuevas circunstancias haga tornar oscura una norma que parecía clara.

\subsection{La interpretación gramatical}

La preeminencia otorgada a la intención común puede conducir al error de querer encontrar una contradicción entre aquella y el texto del contrato, cuando lo natural es lo

11. Véase, G. Ordoqui Castilla, N. 8. 
contrario $^{12}$. Es de asumir que los contratantes han utilizado bien el lenguaje y han acordado en un texto del contrato que expresa adecuadamente la intención común que ellos tuvieron en mente al celebrarlo. Sin embargo, es posible que no exista concordancia entre el texto y la común intención por una variedad de factores. Escasas habilidades de redacción, falta de revisión y cuidado son solo algunos factores. Por otro lado, la riqueza del lenguaje y la diversidad de maneras en emplearlo es enorme.

En el derecho ecuatoriano, la norma del art. 1576 del Código Civil reconoce de manera implícita la interpretación del tenor literal del contrato y señala: "Conocida claramente la intención de los contratantes, debe estarse a ella antes que a lo literal de las palabras"13.

Como se ve, esta norma se enfoca directamente en una hipótesis de conflicto entre la intención común de las partes y lo literal de las palabras del contrato. Pero, como se ha dicho, esta es una situación de excepción.

Más apropiada resulta, a mi juicio, la norma del art. 1281 del Código Civil español que expresa: "Si los términos de un contrato son claros y no dejan duda sobre la intención de los contratantes se estará al sentido literal de sus cláusulas. Si las palabras parecieren contrarias a la intención evidente de los contratantes, prevalecerá esta sobre aquellas".

Enesta disposición se distinguen claramente dos supuestos. El primero, el de claridad de los términos del contrato y coincidencia

12. En este sentido OsPinA señala: "Pero mientras no esté 'claramente' establecida, como lo exige el comentado texto legal, la antítesis entre la intención de los contratantes y la declaración que estos hacen de ella, el intérprete debe respetar esta declaración, y esto por la razón obvia de que es de presumir que los términos empleados por los agentes lo han sido conscientemente; que estos han materializado su verdadero querer interno, o sea, que lo han interpretado de modo auténtico". G. Ospina Fernández, \& E. Ospina Acosta, Teoría general del contrato y del negocio jurídico, Temis, 2000, p. 405.

13. Código Civil, N. 1, Art. 1576. 
indubitable entre ellos y la intención de los contratantes. En este supuesto, se estará al sentido literal de sus cláusulas.

Diez-PicAzo ha señalado con agudeza que esta norma no debe entenderse como una exclusión de la interpretación en los casos de claridad, sino como una presunción a favor del sentido literal y, citando a JORDANO BAREA, indica que lo que se trata de impedir es que, so pretexto de interpretación, resulte tergiversada una declaración que realmente es clara ${ }^{14}$.

En el segundo supuesto, cuando pareciere que las palabras fuesen contrarias a la intención evidente de los contratantes, prevalece la intención.

\subsection{La interpretación lógica y sistemática}

Tal como destaca la doctrina, en esta materia tiene gran importancia el "canon hermenéutico de la totalidad" (BЕTTI), es decir, la interpretación sistemática del contrato. Nuestro Código Civil lo acoge en el inciso primero del art. 1580 cuando dispone que "[1]as cláusulas de un contrato se interpretarán unas por otras, dándose a cada una el sentido que mejor convenga al contrato en su totalidad"15.

Es importante anotar que la interpretación sistemática es siempre necesaria y no se trata de una regla subsidiaria, pues interpretar una cláusula sin tener en cuenta el contrato en su conjunto pone en riesgo la correcta comprensión del significado de ella, ya que, como ha señalado BIANCA ${ }^{16}$, incluso una cláusula aparentemente clara se debe ver y entender en el marco del conjunto unitario que es el contrato.

La interpretación sistemática es de innegable valor para determinar la intención pues, como ha dicho el Tribunal Supremo

14. L. Diez-Picazo, N. 5, p. 501-502.

15. Código Civil, N. 1, Art. 1580.

16. M. Bianca, Derecho Civil, Tomo 3: El Contrato, 1era Ed., Editorial Cordillera, 2007, p. 453. 
Español, "[1]a intención, que es espíritu del contrato, es indivisible, no pudiendo encontrarse en una cláusula aislada de las demás sino en el todo orgánico que constituye ${ }^{17}$. En igual sentido, nuestra Corte Nacional de Justicia ha señalado que la norma del art. 1580 del Código Civil (antes 1607) obliga al intérprete a que en el caso de que existan en un contrato varios acuerdos de voluntad, que forman una unidad, todas y cada una de sus cláusulas deben ser apreciadas en conjunto y con coordinación y armonía ${ }^{18}$.

La interpretación sistemática lleva a evitar o superar las antinomias y contradicciones y determinar cuáles son las disposiciones de carácter principal frente a las accesorias. Esta interpretación puede y debe aplicarse no solo a las cláusulas de un mismo contrato sino también a la relación que varios contratos puedan tener dentro de una unidad negocial compleja, cuando todos ellos se celebren para conseguir una finalidad económica unitaria ${ }^{19}$.

Nuestro Código Civil acoge esta idea en el inciso segundo del art. 1580 cuando señala: "Podrán también interpretarse por la de otro contrato entre las mismas partes y sobre la misma materia" ${ }^{20}$. El ámbito de esta norma, sin embargo, es más amplio, porque abarca también a diversos contratos así no formen estos parte de la misma unidad negocial.

\subsection{El método histórico}

La interpretación histórica de las circunstancias en las cuales se celebró el contrato, los antecedentes, negociaciones y trabajos preparatorios pueden arrojar luz para que el intérprete conozca la situación concreta jurídica y económico-social en que las partes se encontraban al celebrar el contrato y lo que buscaban conseguir con su celebración. En el conocimiento

17. Tribunal Supremo de España, STS de 15-feb-75, citado por L. Diez-Picazo, N. 5, p. 502.

18. Colección de Jurisprudencia 2000-II-Civil, Fallo Civil 8-2000, pp. 215-224.

19. Véase, L. Diez-Picazo, N. 5, p. 502.

20. Código Civil, N. 1, Art. 1580. 
detallado de las circunstancias históricas en que se celebró un contrato puede estar la clave para entender cuál fue la intención común de ellas al celebrarlo.

También puede ayudar a la interpretación la manera como las partes hayan aplicado o ejecutado el contrato voluntariamente, o una de ellas con aprobación de la otra. Este es el llamado "comportamiento interpretativo", que nuestro Código Civil acoge en el inciso tercero del art. 1580 como pauta de interpretación.

\subsection{La interpretación finalista}

Es innegable que para conocer el sentido de un contrato resulta esencial averiguar cuál era el objetivo principal que guiaba a los contratantes, cuál era la concreta situación económico-social que ellos pretendían que cumpla el contrato, pues ello es su última razón de ser.

A preguntarnos todo ello nos conduce el art. 1579 del Código Civil ecuatoriano, cuyo texto expresa en el inciso primero: "En los casos en que no apareciere voluntad contraria, deberá estarse a la interpretación que más bien cuadre con la naturaleza del contrato".

La expresión "naturaleza del contrato" se refiere al tipo de contrato, que puede ser nominado o atípico y, en consecuencia, exige averiguar y considerar la función económico-social que está llamado a cumplir. Por su parte, la expresión inicial de la norma, "En los casos en que no apareciere voluntad contraria", luce como una reiteración de la amplia autonomía con que cuentan los contratantes para escoger un determinado tipo contractual, para excluir o modificar ciertas normas que usualmente formarían parte del mismo. Naturalmente, esta alternativa es posible solamente en cuanto se trate de normas supletorias y no de carácter imperativo. 
Ya en el orden práctico, la averiguación de la finalidad concreta buscada por las partes al celebrar un contrato debe ser una de las primeras actividades que realice el intérprete, pues ello le permitirá realizar la calificación del mismo y dar luces para determinar la intención común que tuvieron al celebrarlo.

Otra expresión del criterio finalista como pauta para la interpretación es la norma contenida en el art. 1578, que recoge el principio de conservación y sentido efectivo. Según dicha norma: "El sentido en que una cláusula pueda surtir algún efecto, deberá preferirse a aquel en que no sea capaz de surtir efecto alguno".

Si bien la norma se refiere sólo al sentido de una cláusula, y no del negocio entero, la doctrina considera que puede aplicarse al contrato en general ${ }^{21}$, pues debe presuponerse cierta dosis de racionalidad en los contratantes que no debieron buscar disposiciones inútiles.

También conviene señalar que la norma del art. 1578 nada dice sobre la posibilidad de que, existiendo una pluralidad de sentidos, en todos ellos el contrato sea eficaz. En este caso habrá de acudirse a los métodos de interpretación subjetiva o al de la interpretación finalista.

\subsection{El principio de buena fe}

Según la norma del art. 1562 de nuestro Código Civil, los contratos deben ejecutarse de buena fe. Si bien la norma se refiere a la buena fe en la ejecución de los contratos y no en la interpretación de ellos, existe un amplio consenso en la doctrina en el sentido de que ella, como principio general del derecho, es de plena aplicación obligatoria al interpretar los contratos. Además, si para ejecutar el contrato es necesario interpretarlo -como ha quedado dicho arriba-, para ejecutarlo de buena fe, su

21. L. Diez-Picazo, N. 5, p. 507. 
interpretación debe considerar necesariamente este elemento. Sería un contrasentido para el sistema aceptar una interpretación contraria a la buena fe. Ello llevaría a permitir que la deslealtad y las argucias triunfen sobre la moralidad y la ética.

Por el contrario, la doctrina ha señalado que, siendo un principio general del ordenamiento jurídico, la buena fe domina todas las formas o métodos de interpretación ${ }^{22}$, sean estos objetivos o subjetivos, pues se trata de un principio éticosocial que irradia toda la materia contractual.

La buena fe es un estándar objetivo constituido por lo que una persona razonable habría entendido en las circunstancias en las que se celebró el contrato, y ese entender debe ser tenido en cuenta al momento de interpretar el contrato, pues viene exigido por la confianza razonable que se ha podido generar en el contratante.

Esa confianza razonable se determina, dice BIANCA ${ }^{23}$, según lo que una parte haya hecho entender a la otra por medio de sus declaraciones y comportamientos, valorados según el parámetro de la diligencia normal. La buena fe impone (i) no suscitar una falsa confianza; (ii) no especular con esa falsa confianza; y, (iii) no desconocer la confianza razonable generada a la otra parte.

Por otra parte, señala el mismo autor ${ }^{24}$ se prohíben interpretaciones capciosas en contradicción con la causa del contrato y el espíritu del acuerdo. El contrato debe ser interpretado de manera que el sentido que se le atribuye sea el más conforme con la lealtad y las normas éticas ${ }^{25}$.

Una clara aplicación del principio de buena fe es la regla de interpretación contractual contenida en el inciso segundo

22. A. ARIZA, Interpretación de los contratos, Editorial Hammurabi, 2005, p. 444.

23. M. BIANCA, N. 16, p. 445.

24. Ídem, pp. 445-446.

25. Véase, L. Diez-Picazo, N. 5, p. 500. 
del art. 1582 del Código Civil, que consagra la llamada "carga de hablar claro".

Según dicha norma, "las cláusulas ambiguas que hayan sido extendidas o dictadas por una de las partes, sea acreedora o deudora, se interpretarán contra ella, siempre que la ambigüedad provenga de la falta de explicación que haya debido darse por ella".

El principio de la buena fe postula que quien emite una declaración debe ser responsable de lo que dice y que debe protegerse la confianza de quien es destinatario de la misma.

La carga de hablar claro significa que quien emite la declaración, quien redacta la respectiva cláusula, debe expresarse de forma tal que el destinatario entienda el sentido real de lo que se declaró, y si la declaración es ambigua, ella deberá interpretarse en contra del contratante que emitió, redactó o es responsable de tal declaración.

La regla que estamos comentando, que es conocida también como de la "interpretación contra el estipulante", es de aplicación en los contratos de adhesión y en las condiciones generales de la contratación, cuando el contrato es redactado por una de las partes y la otra simplemente se adhiere al mismo, pero también se aplica a otros casos en que la declaración de la cláusula ha sido efectuada por una sola parte, como en los casos de oferta preparada por una parte y aceptada por otra, o casos en los que una de las partes se encarga de la redacción del documento o de la específica cláusula en la que existe la ambigüedad.

Explicando la operatividad del principio de buena fe ante la emisión de declaraciones equívocas, LARENz ha indicado que, "si quien emite una declaración lo hace de forma equívoca e 
induce al error, es responsable de los medios de expresión por él utilizados" ${ }^{26}$. Sin duda la norma que comentamos recoge esta idea.

\section{Posibilidad de una interpretación derogatoria}

Conviene tener presente que puede darse el caso en que ambos contratantes hayan convenido en un acuerdo que sea ininteligible y ello haga imposible determinar su sentido. En otras palabras, puede ocurrir que ambas partes hayan incumplido la regla de hablar claro.

La situación indicada no se encuentra prevista expresamente en nuestro ordenamiento, pero creemos que la consecuencia de esta patología debe ser la nulidad del contrato.

Esa es la consecuencia prevista en el Código Civil español, en cuyo art. 1289, inciso final, se indica:

Si las dudas de cuya resolución se trata en este artículo recayesen sobre el objeto principal del contrato, de suerte que no pueda venirse en conocimiento de cuál fue la intención o voluntad de los contratantes, el contrato será nulo ${ }^{27}$.

La causal de nulidad podría ser la falta de objeto pues un acuerdo en el que es imposible determinar cuál es el compromiso u obligación que contraen las partes carece de objeto.

La extrema frecuencia con que los árbitros se ven abocados a interpretar contratos para resolver los casos sometidos a su decisión, es extrema. Por ello me ha parecido pertinente dedicar este breve ensayo a repasar los aspectos, en mi opinión más relevantes, de este tema siempre actual.

26. Citado por G. Ordoqui Castilla, N. 8, p. 334.

27. Código Civil español. Art. 1289. 